\title{
OS SUJEITOS EM TEMPOS COMPLEXOS À LUZ/SOMBRA DA ONTOLOGIA DE EDGAR MORIN
}

\author{
Luciana Pacheco Marques (UFJF) * \\ Alan Willian de Jesus (UFJF) **
}

\begin{abstract}
RESUMO
Neste texto, situamos a questão do sujeito à luz/sombra do pensamento de Edgar Morin, que necessita de uma autoética, de uma autocrítica, de ensinar a condição humana, considerando a questão do ser e do saber no pensamento complexo, dadas as desordens e incertezas destes tempos complexos.
\end{abstract}

Palavras-chave: Tempo. Complexidade. Edgar Morin.

\begin{abstract}
THE SUBJECT WITHIN COMPLEX TIMES IN LIGHT/SHADOW OF EDGAR MORIN ONTOLOGY

In this paper, we place the question of the subject in light/shadow of the thought of Edgar Morin, which needs a self-ethics, a self-critical, to teach the human condition, considering the question of being and knowledge in complex thinking, given the disorders and uncertainties of these complex times.
\end{abstract}

Keywords: Time. Complexity. Edgar Morin.

\section{RESUMEN}

\section{LOS SUJETOS EN TIEMPOS COMPLEJOS A LA LUZ/SOMBRA DE LA ONTOLOGIA DE EDGAR MORIN}

En este texto, se coloca la cuestión del sujeto a la luz/sombra del pensamiento de Edgar Morin, que necesita de una autoética, de una autocrítica, de enseñar la condición humana, teniendo en cuenta la cuestión del ser y del saber en el pensamiento complejo, teniendo en cuenta los trastornos y falta de fiabilidad de estos tiempos complejos.

Palabras claves: Tiempo. Complejidad. Edgar Morin.

\section{Redemoinho do ser e do saber}

Diante da ideia de desafio, é bom saber que há o risco do erro ontológico, da ilusão, e que o absoluto é, simultaneamente, o incerto. É preciso que tenhamos claro que, em dado momento, engajamos a nossa e outras vidas, na maioria das vezes, sem querê-lo ou sabê-lo. (MORIN, 2008a, p. 29).

Nosso objetivo nesta tessitura é situar a questão

* Doutora em Educação pela Universidade Estadual de Campinas (UNICAMP). Professora Titular da Faculdade de Educação/ Programa de Pós-Graduação em Educação da Universidade Federal de Juiz de Fora (UFJF). E-mail: luciana.marques65@ gmail.com

** Mestre em Educação pela Universidade Federal de Juiz de Fora (UFJF). Coordenador Pedagógico contratado da Secretaria Municipal de Educação de Juiz de Fora. E-mail: alan.faced@yahoo.com.br 
do sujeito à luz/sombra do pensamento de Edgar Morin, considerando a questão do ser e do saber no pensamento complexo, dadas as desordens e incertezas destes tempos complexos; e, para tal, nos debruçamos no estudo teórico de suas obras.

De antemão, faz-se necessária uma reiteração do sujeito à luz da ordem e do caos que agem em nós e que vivem em nós. Isso porque o pensamento racional tentou conceber o sujeito de forma reducionista, tentou excluir "ele" "dele mesmo", ou seja, tentou ignorar os sentimentos que o circundam e são partes integrais que formam o todo. É necessário aprender a aprender, a construir os nossos conhecimentos. Isso não significa que o sujeito não tenha conhecimento algum, ou que precise se "reciclar". Isso não significa que tenhamos de retroceder ao "marco zero" para ressignificar a construção dos nossos conhecimentos (como se isso fosse possível!), a fim de que aprendamos a construir uma morada planetária melhor. Neste ínterim, Morin (2005) defende que é necessário seguir um método - palavra que originalmente significa caminhada - , a fim de que possamos nos alimentar das culturas ao derredor, e que permanentemente (re)construamos a nossa própria. Dessa forma, Morin (2005, p. 36) contempla que:

O retorno ao começo não é um círculo vicioso se a viagem, como bem diz a palavra trip hoje em dia, significa experiência de onde se volta transformado. Então, talvez, nós poderíamos aprender a aprender, aprender aprendendo. Então, o círculo poderia se transformar em um espiral em que o retorno ao começo é precisamente o que o afasta do começo.

Perfilando por essas reflexões, começamos a sentir que vivemos no tempo, pois este, a todo instante, demonstra ser irreversível, ${ }^{1}$ e que, cada vez mais, adentramos e compreendemos que estamos envolvidos num redemoinho espiral, e não o circular que refuta o nosso ir e vir na (re)construção do ser e do saber. Não podemos deixar de admitir que o novo só existe porque o velho foi criado. "A síntese é igualmente uma ferramenta que nos

1 Questão advinda da $2^{\mathrm{a}}$ lei da termodinâmica, cujas bases proporcionam a concepção do tempo irreversível. É admitida por diversas áreas do conhecimento. Para tanto, ver em Prigogine (2002) e as reflexões sobre o tempo complexo em o Método 1: A natureza da natureza (MORIN, 2005). Encontram-se neste texto as referências completas. permite compreender a formação de unidade e de novas totalidades. Mas essas unidades ou essas totalidades são sempre provisórias ou parciais" (MORIN, 2002b, p. 29). Vivenciamos a condição inacabável do ser. Vivemos num movimento de mudança, não da negação de fatores que irão se contrapor para gerar um terceiro, e este passa a ser "a verdade", excluindo as outras partes que o compuseram. Vivemos na dialogicidade, "que abarca a possibilidade de interação e inter-relação de múltiplas perspectivas, [...] que nem se fundem nem se excluem, mas permanecem em tensão e interação" (AZIBEIRO, 2003, p. 96). A ideia linear concebida na Modernidade não se sustenta nesses tempos complexos que vivemos.

É necessário respeitar a realidade, mas nunca se ajoelhar diante dela. Entre os dois polos do ser e do dever-ser, cada qual estéril em si mesmo, desenham-se as mais vigorosas linhas de força. Aceitar! Recusar! Para recusar este mundo é preciso aceitar este mundo. Para aceitar este mundo é preciso recusar este mundo. Aqui começam as dificuldades. Não existe síntese teleguiada. (MORIN, 2002c, p. 33).

É necessária uma autocrítica frente aos nossos processos históricos, e (re)pensar o ser e o saber na direção do inacabável devir humano. A teoria da complexidade discorre com êxito sobre esta proposta. Se colocarmo-nos no real complexo, veremos que vivemos no/com um mundo em que o paradoxo é vivo, em que a ordem e a desordem estão em nós e no mundo, e que o caos é itinerante e intrínseco nas transições evolutivas do planeta.

Somos herdeiros de um pensamento reducionista. Preceitos elaborados por volta do século XVII, principalmente sobre a tutela do pensamento cartesiano, colaboraram para que a cultura ocidental se conformasse sobre as régias da fragmentação do ser e do saber.

Não obstante, turbulências ocorridas na segunda metade do século XX indicavam um novo período. O desenvolvimento tecnológico, a arte em sua mais profunda expressão, a velocidade do desenvolvimento, entre outras coisas, somaram-se a outras grandes mudanças, anunciando que a Modernidade vinha sendo insuficiente para abarcar as necessidades nas quais o sujeito encontra-se imerso, circundado pelas imprevisibilidades. 
Estamos em meio a um redemoinho temporal, onde a ordem e a desordem envolvem-nos, não nos deixando perder de vista a complexidade na qual vivemos e somos parte. Contudo, esses ideais da Modernidade só conseguiram separar conceitualmente o homem, natureza e cultura, mas não em sua essência, não em sua mais profunda expressão. O processo histórico da Modernidade desenvolveu a dicotomia, e expressou-a por diversos cantos do mundo guiada pelo paradigma cartesiano que sobrepujaria o ocidente: "sujeito/ objeto; alma/corpo; espírito/matéria; qualidade/ quantidade; finalidade/causalidade; sentimento/ razão; liberdade/determinismo; existência/essência" (MORIN, 2002c, p. 26).

Vivemos o movimento histórico da Atualidade, e uma autocrítica faz-se necessária frente às nossas construções como sujeitos no mundo. Como vivenciar isso? Como pensar em outra perspectiva, de estarmos imersos em si e no mundo, se este pensar vai de encontro às nossas andanças? Ora, se estivéssemos aqui simplesmente propondo outro modo de se pensar, agir e sentir a nós mesmos e ao mundo, estaríamos encerrando por si só nossos ideais, propondo em si uma perspectiva camuflada, falsa de se conceber o sujeito em suas peculiaridades e (re)organizações. Sendo assim, não se trata de um pensamento de síntese, mas dialógico, que nos convida a não viver a realidade a partir de uma única verdade irrefutável. Não se trata de uma ordem que cancela a desordem. Não é um pensamento que exclui o uno, mas acolhe o múltiplo, aceitando o paradoxo. Não se encerra na aceitação da incerteza por si só, mas admite a incerteza numa teia das ações, dos acasos, das interações e da auto-organização que faz parte de nós, que faz parte do todo.

Morin (2005, p. 36) traz os modos fundamentais do pensamento simplificador, a fim de que (re) pensemos em que está pautada nossa práxis:

- idealizador (acreditar que a realidade possa se reabsorver pela ideia, que o real é inteligível),

- racionalizador (querer encerrar a realidade na ordem e na coerência de um sistema, proibir qualquer transbordamento deste, ter a necessidade de justificar a existência do mundo conferindo-lhe um certificado de racionalidade),
- normalizador (quer dizer, eliminar o estranho, o irredutível, o mistério).

Eu parto também com a necessidade de um princípio de conhecimento que não apenas respeite, mas reconheça o não-idealizável, o não-racionalizável, o que foge às regras, o enorme. Nós precisamos de um princípio de conhecimento que não apenas respeite, mas revele o mistério das coisas.

Ao mergulharmos em nós mesmos, guiados pela lanterna do pensamento complexo - do latim complexus, ou seja, o que se encontra tecido juntamente - guiado pela real possibilidade de estarmos abraçados à natureza e ao Outro, vimo-nos imersos neste princípio. Demo-nos conta de que somos fazedores do nosso tempo e que, ao mesmo tempo, fazemos parte do local e do global, que, juntamente com o religar, formam o objetivo deste pensamento multidimensional, onde, ao mesmo tempo em que busca unir o particular ao global, busca aceitar o desafio da incerteza, questionando o determinismo implícito no discurso da Física Mecânica e na Moderna, e de outras áreas do conhecimento que nos circundam, a qual nos exemplifica Prigogine (2002, p. 20), ao citar uma carta de Einstein a Tagore, ${ }^{2}$ discorrendo que:

Se perguntássemos à Lua por que ela se move, ela responderia sem dúvida que se move porque tomou essa decisão. E isso nos faz sorrir. Mas deveríamos igualmente sorrir da ideia segundo a qual o homem é livre, porque o determinismo não tem nenhuma razão para se deter na fronteira do cérebro. O determinismo é a concepção clássica da ciência.

A Atualidade ${ }^{3}$ revela-nos em toda sua multidimensionalidade a liquidez dos paradigmas da Modernidade perante as nossas construções históricas. Nossa evolução biológica e intelectual é indiscutível, mas não podemos compreendê-la de forma simplista. E é perpassando por algumas nuanças do processo da hominização, a qual Edgar Morin traz como fundamental na constituição da teoria da

2 "Rabindranath Tagore (1861-1941), escritor e místico indiano, Prêmio Nobel de Literatura em 1913.” (PRIGOGINE, 2002).

3 Chamamos de Atualidade o momento que estamos vivendo no mundo hoje. Os paradigmas da Atualidade rogam pelo dobrar dos sinos a uma cabeça cheia, pois mais vale uma cabeça benfeita (MORIN, 2002a). Há a necessidade de se pensar tecido junto, num movimento frenético que anseia por isso, onde as palavras mais perenes duram na composição do efêmero, da incerteza, da crise, da desordem, junto às certezas e ordens. 
complexidade, que vamos ver como coadunam em nós a animalidade e a humanidade que constituem o nosso estofo propriamente humano.

Pois bem, com a revolução Iluminista, os nossos pensamentos e as nossas ideias foram conduzidos pela razão, não sendo por acaso que o século XVII foi entendido como a época do racionalismo. Dito em poucas linhas, a razão pode ser considerada como aquilo que é produto de cálculo - na explanação do professor Ramos (2008) acerca da certeza -, e é a adequação de alguns meios a alguns fins. Dessa forma, se refletirmos sua definição, vamos ver que aprendemos que somos apenas racionais, ou seja, que somos sapiens.

Estamos no primeiro entrelaçamento do pensamento complexo. Ele nos diz que nós somos Homo e também sapiens. Contudo, se dissermos simplesmente que somos Homo sapiens, estamos somente nos identificando num contexto mais amplo, ou seja, estamos nos remetendo à ideia de que somos homem e de que também somos como os nossos parentes mais próximos (primatas tais como gorilas, chipanzés etc.). Múltiplas são as relações e as interferências do meio, além de fatores genéticos e, mais adiante, os fatores culturais que auxiliaram no processo dinâmico/simultâneo, o qual vai trazer o aparecimento do Homo sapiens.

A hominização é real, mas não é somente o que aparece, é também o que desaparece. Os estudos antropológicos nos mostram este caminho pela Pré-História. Dessa forma, "a hominização conduz a novo início. O hominídeo humaniza-se. Doravante, o conceito de homem tem duplo princípio; um princípio biofísico e um psico-sócio-cultural, um remetendo ao outro" (MORIN, 2002c, p. 51).

Mediante essas considerações, houve a necessidade de ganharmos mais um sapiens. Entretanto, Morin (1975) contempla que, se nós nos considerarmos apenas Homo sapiens sapiens, ainda estaríamos sendo sistemáticos demais, ou seja, que nós falamos, que nós descemos das árvores, que comunicamos e simbolizamos. Dito em outros termos, nós simplesmente construímos representações. Assim sendo, Morin (2002c, p. 51) considera que:

A antropologia pré-histórica mostra-nos como a hominização é uma aventura de milhões de anos, ao mesmo tempo descontínua - surgimento de novas espécies: habilis, erectus, neanderthal, sapiens, e desaparecimento das precedentes, aparecimento da linguagem e da cultura - e contínua, no sentido de que prossegue em um processo de bipedização, manualização, erguimento do corpo, cerebralização, juvenescimento (o adulto que conserva os caracteres não-especializados do embrião e os caracteres psicológicos da juventude), de complexificação social, processo durante o qual aparece a linguagem propriamente humana, ao mesmo tempo que se constitui a cultura, capital adquirido de saberes, de fazeres, de crenças e mitos transmitidos de geração em geração [...]

Contudo, lentos são os nossos passos. Uma longa jornada viva/evolutiva ocorre em meio a uma cascata de acontecimentos de ordem-desordem a todo instante. Uma certa perturbação no sistema organizacional já começa a se manifestar amiúde. $\mathrm{O}$ homem começa a perceber que algo lhe parece não obedecer à relação fenomênica que ele considerava sistemática. Entretanto algo salienta. O dito sapiens sapiens começa também a perceber que muitas questões parecem obedecer ao acaso, mas que este advém de si mesmo. O homem começa a ver que, ao mesmo tempo em que o êxtase do descobrimento eclode, emerge-se concomitantemente o humano do humano, desobedecendo assim à ordem. O próprio homem é glorificador e perturbador da emissão de suas mensagens.

Poder-se-ia ter a impressão de que estamos à mercê de um efêmero linear, mas o que nos envolve é um redemoinho temporal experienciado e vivido de forma única por cada um de nós. Uma reconciliação ${ }^{4}$ urge nestes novos tempos, trazendo-nos “A nova aliança” (PRIGOGINE, 2002); e uma eterna aliança estará em nós: natureza e cultura! A humanidade está no humano, e o humano na humanidade. Todavia essa questão, ao mesmo tempo em que nos envolve com seu manto pertinente, comporta o antagonismo, admitindo a perdição. Somos concomitantemente parte do cosmos e estranhos a ele. Nossas atitudes para com a natureza que nos circunda, para com as culturas diferentes das

4 Palavra-chave do sistema elaborado por Ilya Prigogine (2002, p. 14): "Reconciliação do homem com a natureza. Reconciliação da ciência com a filosofia. Em outras palavras, La nouvelle alliance [A nova aliança], celebrada a duas vozes, em 1979, com Isabele Stengers, um livro acontecimento que marcará época na história da epistemologia, e que será seguido, em 1988, por Entre Le temps et l'éternité [Entre o tempo e a eternidade], sempre em colaboração com sua colega química e filósofa." 
nossas, e para conosco, nos mostram um descaso tênue com o humano do humano. Gradativamente evoluímos. Gradativamente... em uma instância biofísica e psicossociocultural. Contudo, gradativamente vimos admitindo mais o lado obscuro de nós mesmos e de nós outros. Gradativamente a cegueira vem ocupando nosso espírito. Uma cegueira paradigmática enraizou-se em nossa alma de forma bem sutil, mas cancerígena. A evolução também nos deixou cegos para a cegueira - construída por nós em nós, fundada na razão pura - que, assim como a evolução, ela, aos poucos, naturalizou-se em nosso ser. Uma ciência mais nobre e um pensamento mais humilde fazem-se necessários. Será que realmente avançamos o quanto achamos? Reconhecemos nossos passos lentos perante os longos tempos que vivemos e os longínquos tempos que nos esperam.

A Atualidade atina-nos para esta caminhada, mostrando-nos um caminho a ser construído por nós. Não num porvir, mas no agora complexo em que estamos e de que somos parte. Pois, "desenvolvemo-nos além do mundo físico e vivo. É neste 'além' que tem lugar a plenitude da humanidade" (MORIN, 2002c, p. 51).

\section{Da necessidade de princípios que nos religuem}

Temos indícios de uma incerteza na qual estamos envoltos, sendo que a concepção mecanicista das certezas não contempla o homem em sua totalidade, passando-nos o ideal do "ou”, ou seja, "ou uma coisa ou outra". "O transeunte das áreas do conhecimento" propõe um novo olhar, denunciando a visão unilateral que define o ser "humano pela racionalidade (Homo sapiens), pela técnica (Homo faber), pelas atividades utilitárias (Homo economicus), pelas necessidades obrigatórias (Homo prosaicus). O ser humano é complexo e traz em si, de modo bipolarizado, caracteres antagonistas" (MORIN, 2002c, p. 58).

A complexidade, na qual vivemos e somos parte, nos possibilita ir em direção ao amanhecer urgente ao qual precisamos vivenciar. Trazemos em si o "e" por natureza, mesmo que o neguemos. Neste caso, vemos que a negação de si próprio somente levará ao caminhar por uma vida deserta, insaciável por um lampejo de conseguir amar a si mesmo, uma vez que a vida não tem sentido se não amarmos. Doravante, "nestes tempos complexos", o compreender a si mesmo exige, a priori, o amar o Outro, porque o amor só existe com a existência do Outro. Por isso que a vida só tem sentido quando o Outro existe. O delírio do Outro, a imaginação do Outro, o consumo do Outro, a alegria do Outro... e o amor do Outro são o que movimentam a vida. Assim, pois,

O homem da racionalidade é também o da afetividade, do mito e do delírio (demens). O homem do trabalho é também o homem do jogo (ludens). O homem empírico é também o homem imaginário (imaginarius). O homem da economia é também o do consumismo (consumans). O homem prosaico é também o da poesia, isto é, do fervor, da participação, do amor, do êxtase. O amor é poesia. Um amor nascente inunda o mundo de poesia, um amor duradouro irriga de poesia a vida cotidiana, o fim de um amor devolve-nos à prosa. (MORIN, 2002c, p. 58).

Por mais que o pensamento racional, pautado nas teorias desenvolvidas no século XVII (sobretudo o Método da certeza), tenha nos levado a questões dicotômicas, nós nunca deixamos de produzir cultura. Fizemos um caminho que nos levou da ordem biológica à sapiência, mas também à loucura. Pode um sapiens que não é capaz de criticar sua própria sapiência ser digno de ser sapiens? O homem não vive só da racionalidade, nós também nos desgastamos, dançamos, temos ritos, cremos naquilo que nossos olhos não podem ver, acreditamos que a vida não cessa, cremos que o amor transcende a existência além da vida corpórea...

Surge, então, a face do homem escondido pelo conceito tranquilizador e emoliente do sapiens. Trata-se de um ser de uma afetividade imensa e instável, que sorri, ri, chora, um ser ansioso e angustiado, um ser gozador, embriagado, extático, violento, furioso, amante, um ser invadido pelo imaginário, um ser que conhece a morte e não pode acreditar nela, um ser que segrega o mito e a magia, um ser possuído pelos espíritos e pelos deuses, um ser que alimenta de ilusões e de quimeras, um ser subjetivo cujas relações com o mundo objetivo são sempre incertas, um ser submetido ao erro, ao devaneio, um ser híbrico ${ }^{5}$ que produz a desordem. É como chamamos loucura à conjunção da ilusão, do descomedimento,

5 Neologismo formado sobre o grego hybris, descomedimento. 
da instabilidade, da incerteza entre real e imaginário, da confusão entre subjetivo e objetivo, do erro, da desordem, somos obrigados a ver o homo sapiens como homo demens (MORIN, 1975).

Somos, ao mesmo tempo, uno e múltiplo. Todo uno está na multiplicidade, assim como o múltiplo faz parte da unidade e o singular traz em si o cosmos no instante, no presente, no imediato, no futuro, no devir. Alcançamos os "paroxismos de vida em êxtase e na embriaguez" (MORIN, 2002b, p. 52). Caímos na malha fina de nossas próprias paixões e dos nós atados. Vamos de um extremo ao outro num piscar de olhos. Choramos, rimos, brincamos, melindramos quando nossos orgulhos são lembrados por aqueles que amamos. Apaixonamos, odiamos, fazemos prosa... amamos... "o ser humano é um animal insuficiente, não apenas na razão, mas é também dotado de desrazão" (MORIN, 2008a, p. 7). É neste entrelaçamento, é neste caminhar pelo "e" e pelo "também" que vemos a necessidade de religarmos todos estes "Homos" e outros mais em um só. Somos Homo sapiens e também Homo demens. Estamos Homo sapiens sapiensdemens.

$\mathrm{O}$ primeiro entrelaçamento do pensamento complexo, ou seja, de sermos Homo sapiens sapiensdemens é fundamental para compreendermos a ontologia de Edgar Morin. Poder-se-ia pensar que a demência humana é fundadora de uma fonte de crueldade e de cegueira. No entanto, sem as lápides dos delírios, nós outros não conseguiríamos inventar e reinventar. Não teríamos a poesia nem a arte, cuja aparente loucura da escrita e das pinceladas "sem nexo" podem representar um mundo que habita em nós. Se, por um lado, as nossas mãos podem se estender para o progresso da ciência, economia e democracia, por outro lado, estas mesmas mãos podem oprimir outrem, banalizando a vida em prol de nossos orgulhos, sugando da natureza bens para nosso bem-estar, sem nos darmos conta do mal-estar e a perspectiva tenebrosa de vida que nós podemos viver, e que nossos descendentes poderão experienciar. Apesar de vivermos uma condição antagônica, Morin (2008a, p. 8) diz que:

Temos, entretanto necessidade de controlar o homo demens para exercer um pensamento racional, argumentado, crítico, complexo. Temos necessidade de inibir em nós o que o demens tem de homicida, malvado, imbecil. Temos necessidade de sabedoria, o que nos requer prudência, temperança, comedimento, desprendimento.

Prudência sim, mas isso não significa esterilizar nossas vidas, evitar riscos a qualquer custo? Temperança sim, mas será mesmo necessário evitar a experiência da 'consumação' e do êxtase? Desprendimento sim, mas será mesmo necessário renunciar aos laços de amizade e amor?

O mundo em que vivemos talvez seja um mundo de aparências, a espuma de realidade mais profunda que escapa ao tempo, ao espaço [...]. Mas nosso mundo da separação, da dispersão, da finitude significa também o mundo da atração, do reencontro, da exaltação. [...] Não experimentá-lo é evitar o sofrimento, mas também não haverá o gozo.

Confessamos que é difícil aceitar o paradoxo existente em nós. No entanto, não podemos omitir uma interrogação. Se vivemos em meio ao turbilhão das nuanças de acontecimentos, acasos, incertezas, retroações, ações, (in)determinações, interações..., como podemos negar nossos traços inquietantes deste emaranhado complexo? Neste mundo incerto, cujas relações oscilam, o único absoluto que nós podemos admitir é a presença do amor, na medida em que cansamos de nossa própria sapiência e esforcemo-nos para domar o nosso lado obscuro. Assim, pois, confiamos e aceitamos que a demência incontrolável, nossas malvadezas, a racionalização pura, não passam de uma mera ausência do amor. Bem, sabemos que se for perguntado para nós o que é este sentimento sublime, dificilmente saberíamos responder. Contudo, se este vem ao nosso encontro através dos ventos da complexidade, nós o reconhecemos. Se não estamos satisfeitos com a realidade submersa em circunstâncias promíscuas, não esperemos que a mudança comece pelo Outro, e sim contaminemos o Outro com a nossa vontade de ser mais do que apenas um andarilho negador de sua própria natureza complexa, deixando-se seduzir pelas torpezas mundanas, pelas cegueiras que extirpam de nós mesmos a sensibilidade humana do humano no entrelaçamento complexo de que fazemos parte.

Necessário, entanto, faz-se um segundo, fundamental para compreendermos a noção do sujeito complexo. Um segundo entrelaçamento urge, a fim de mergulharmos ainda mais na ontologia deste "Navegador das áreas do conhecimento". 
Falaremos dos princípios que buscam unir o contexto ao global e observemos o quão o dogma do determinismo se desfalece a cada enunciado revelado pela aceitação das incertezas que estão nas estradas do conhecimento, afetando também nossa forma de ver o mundo. Sem instituirmos uma organização hierárquica, veremos os princípios que se complementam em suas particularidades, a fim de pensarmos a complexidade e suas práticas da produção do conhecimento.

O primeiro é o princípio sistêmico ou organizacional, que liga o conhecimento das partes ao conhecimento do todo. É importante lembrar que a organização não se reduz à ordem, pois, no pensamento complexo, a ordem caminha no binômio com a desordem (ordem-desordem), mas isso não quer dizer que a ordem não seja compreendida. "Do átomo à estrela, da bactéria ao homem e à sociedade, a organização do todo produz qualidades ou propriedades novas em relação às partes consideradas isoladamente: as emergências" (MORIN, 2003 , p. 15). Cabe ainda ressaltar que a totalidade é sempre aberta. Isso significa que, no pensamento complexo, a totalidade tanto pode ser mais ou eventualmente ser menos que a soma.

O todo é uma unidade complexa. E o todo não se reduz a mera soma dos elementos que constituem suas partes. É mais do que isto, pois cada parte apresenta sua especificidade e, em contato com as outras, modificam-se as partes e também o todo. (PETRAGLIA, 2008, p. 59).

Sendo assim, a complexidade nos faz compreender que, jamais poderemos escapar da incerteza e que jamais poderemos ter um saber total: 'A totalidade é a não-verdade’. (MORIN, 2007, p. 69).

Outro princípio é o hologramático. Este "coloca em evidência o aparente paradoxo dos Sistemas complexos, onde não somente a parte está no todo, mas o todo se inscreve na parte" (MORIN, 2003, p. 15). Justificamos, neste princípio, nossos dizeres em certos momentos deste trabalho, ao ressaltarmos que somos parte do todo e que o todo faz parte de nós, pois que, na sociedade como um todo, cada indivíduo encontra-se ligado de alguma forma - tecido junto -, como se estivéssemos em uma grande teia, em que qualquer movimento em suas extremidades ou nas regiões centrais faz com que toda a teia vibre. Toda ela sente e se deixa ser sentida pelos acasos e as indeterminações que a afetam. De alguma forma, as ações de outrem chegam até nós, seja de forma mais intensa, ou seja, de forma mais branda. Lembremos, no entanto, que cada um sente as ações do cosmo conforme o que a nossa historicidade construiu e vem construindo a cada instante, conforme o que existe de demens em nós. Assim sendo, podemos potencializá-la, ou diminuí-la, quem sabe, ou mesmo deixá-la estável. São elas... as vibrações da teia, em outras palavras, os antagonismos, as incertezas, os acontecimentos, as interações, as determinações, os acasos... enfim, a complexidade que constitui o nosso mundo real e virtual numa simultaneidade do limite entre a loucura e a sensatez: a complexidade de cada ser, que emerge num devir cósmico, não se limitando a uma mera qualidade de cada parte que compõe o todo, mas uma parte que influencia e forma outras partes no caminho das emergências. Ao mesmo tempo em que somos autônomos, somos dependentes, assim, pois, o local faz parte do global e vice-versa, porque a cultura e a natureza nos possibilitam isso. Dessa forma, este princípio opõe-se à ideia separatista, advinda da concepção de separação entre o homem e a natureza de outrora.

A ideia era a de que, para o conhecimento do homem, deveríamos rechaçar, eliminar tudo o que fosse natural, como se nós, o nosso corpo e organismo fossem artificiais, ou seja, a separação total. A separação do sujeito e objeto, significando que nós temos o conhecimento objetivo porque eliminamos a subjetividade. Sem pensar que no conhecimento objetivo há, também, a projeção de estruturas mentais dos sujeitos humanos e, ainda, sob condições históricas, sociológicas, culturais precisas (MORIN, 2008c).

Fato é que vivemos em sociedade, e que numerosos eixos temáticos e áreas do conhecimento nos circundam. Há uma tendência a se conceber que uma causa gera um efeito e ponto final na área da educação, por exemplo, quando pautada e refletida sob o viés da lógica do determinismo clássico. Ora, sabemos que grandes são as desavenças oriundas de uma causa. No entanto, determiná-las linearmente, como uma geração de efeito, nos coloca na presilha entre os limiares da certeza e do acabamento. Contudo, a complexidade nos apresenta o princípio 
do anel retroativo, a partir do qual se "permite o conhecimento dos processos de autorregulação, rompendo assim com a causalidade linear" Morin (2003, p. 16). Dessa maneira, uma questão pode ser advinda de inúmeras possibilidades de causas, que podem se tornar um efeito. Todavia isso não quer dizer que seja rígido, pois neste anel retroativo entende-se que o efeito também está num movimento constante, tornando-se causa de um produto, rompendo assim com a estática.

Adentremo-nos no anel recursivo. Aqui, justifica-se pela dinâmica existente entre sujeito e objeto. Aqui, a dicotomia cartesiana escorre por nossas mãos. "É um anel gerador, no qual o produto e os efeitos são produtores e causadores do que os produz" (MORIN, 2003, p. 16). Isso significa dizer que a causa produz o efeito, que produz a causa, resumindo-se num circuito recursivo. Edgar Morin nos traz como exemplo a nossa própria existência, que é produto da união biológica entre um homem e uma mulher e, ao mesmo tempo, seremos produtores de outras uniões. Nesse sentido, nós somos recursivamente causa e efeito.

Outro princípio é o da auto-eco-organização. Este nos mostra o quão os seres humanos são capazes de emergir ao mesmo tempo no/com o mundo - junto com o todo - a partir de sua auto-organização, intrínseca à autonomia e à dependência. "Para transformar-se e conhecer-se, o sujeito necessita de um objeto. É a partir dessa dependência que o sujeito e o objeto emergem da realidade complexa, assim como se observa na relação recíproca e inseparável: sistema auto-eco-organizador e ecossistema" (PETRAGLIA, 2008, p. 69). Temos, então, que o sujeito possui autonomia para caminhada autodidata. No entanto, somos seres dependentes, pois que necessitamos não somente do objeto, mas também do Outro. Afirma Edgar Morin (2003, p. 17) que:

Um aspecto determinante de auto-eco-organização é que esta se regenera em permanência a partir da morte de suas células, conforme a fórmula de Heráclito, 'viver de morte, morrer de vida', e que as duas ideias antagônicas de morte e vida são aí complementares, mesmo permanecendo antagônicas.

Temos então o princípio dialógico - que consiste no entendimento da dialogia -, que significa entrelaçar coisas que aparentemente estão separadas como a razão e a emoção, o real e o imaginário. Não exclui um ou dois princípios, a fim de que nasça um terceiro, mas consiste em uni-los, pois, numa mesma realidade, eles são indissociáveis. Falamos ao longo do texto sobre a necessidade de se pensar em conjunto; aliás, quando remetemo-nos à complexidade, logo pensamos em algo difícil, muito complicado... Contudo, adverte-nos Morin (2007) que é necessário buscarmos na etimologia da palavra complexus, que significa "aquilo que é 'tecido' junto".

Pensar na perspectiva da complexidade, então, é como pensar num tecido em que os fios paralelos não são apenas amarrados, confundindo-se, mas unidos transversalmente por uma trama que os religa. A partir desse paradigma de pensamento e ação, entender a realidade não significa decompô-la em elementos simples, isolando-os uns dos outros, mas buscar percebê-la em suas múltiplas composições e interações, em suas diferentes redes de significados. O pensamento complexo não se reduz à ciência, à filosofia, à arte ou a qualquer campo específico do saber, mas permite sua comunicação, como se fosse uma naveta que trabalha para unir os fios (AZIBEIRO, 2003).

Dessa forma, observamos que a dialogia permite a associação de noções contraditórias, procurando conceber um mesmo fenômeno complexo, no qual podemos ver que não é possível entender a realidade a partir de uma única verdade. Sendo assim, no pensamento complexo não há síntese.

E, por fim, o princípio da reintrodução, que anuncia o conhecimento como um emaranhado de possibilidades abertas numa teia entrelaçada, e não uma concepção linear. "Esse princípio opera a restauração do sujeito e ilumina a problemática cognitiva central: da percepção à teoria científica, todo conhecimento é uma reconstrução/tradução por um espírito/cérebro numa certa cultura e num determinado tempo" (MORIN, 2003, p. 18).

Apesar de termos citado todos esses princípios, o "precursor da teoria da complexidade" diz que, para se constituírem as formas não lineares e não compartimentadas, ou seja, para nos ajudar a pensar a complexidade, destacam-se três operadores ou princípios, dentre os quais nós citamos, construindo a noção de totalidade: o hologramático, o recursivo e o dialógico, os quais Morin denomina como os 
que põem em movimento o pensamento complexo. Contudo, não se trata de expulsar a certeza com o princípio da incerteza. Não coloquemos a complexidade num pilar de adorações, pois assim estaríamos compreendendo-a da mesma forma excludente com que as ideias simplificadoras o fazem. "Trata-se de entender o pensamento que separa e que reduz, no lugar do pensamento que distingue e une. Não se trata de abandonar o conhecimento das partes pelo conhecimento das totalidades, nem da análise pela síntese; é preciso conjugá-las" (MORIN, 2002c, p. 46).

Portanto, fica claro que temos obstáculos criados acerca da racionalização (o que consiste em prender a realidade num sistema coerente, e tudo que na realidade contradiz este sistema coerente é posto de lado, visto como uma ilusão), que é um esforço de adequação entre os meios e fins. Sendo assim, Edgar Morin (2002c) faz uma abordagem da complexidade em qualquer instância de qualquer sistema vivo. Desse modo, para Morin (2007), qualquer unidade é guiada por uma tetralogia que envolve relações de ordem, desordem, reorganização e interação. É justo e necessário elencarmos esses conceitos. Talvez agora, nós que estávamos confusos, que não sabíamos mais se estávamos num complexo real ou imaginário; que já não mais sabíamos se existia ordem ou desordem, ou os dois; se tudo que achávamos que era certo ou errado conforme nossas construções históricas agora faz parte de uma grande ilusão; ou até mesmo se a organização na verdade é uma camuflagem de nossa desorganização..., possamos nós, sob a luz do pensamento complexo, adentrarmos ainda mais nas nuanças da ontologia do "pioneiro da complexidade".

Tratemos do conceito de ordem. Petraglia (2008, p. 65) discorre que:

Transcende a antiga ideia determinista de estabilidade, permanência, imutabilidade e constância, pois encerra também em seu termo a noção de singularidade presente em seu nascimento e desenvolvimento peculiares a cada coisa; como também compreende em seu bojo a ideia das interações, o que significa que nada existe sem influências (internas e externas) e sua interdependência.

A desordem traz, em sua ideia, desvios que aparecem em qualquer processo, alterando-os de forma inesperada, em que no homem pode-se nomear este fato de incerteza, a qual Morin (2008b) classifica como crucial para a evolução do universo.

Caminhando para o agrupamento do tetragrama, faz-se necessário o conceito de organização, trazendo a ideia de que:

[...] a organização é disposição de relações entre componentes ou indivíduos, que produz uma unidade complexa ou sistema, dotada de qualidades desconhecidas ao nível dos componentes ou indivíduos. A organização liga, de modo inter-relacional, elementos ou acontecimentos ou indivíduos que, a partir daí, se tornam os componentes dum todo. Garante solidariedade e solidez relativa a estas ligações, e portanto garante ao sistema uma certa possibilidade de duração apesar das perturbações aleatórias. Portanto a organização: transforma, produz, liga, mantém. (MORIN 1997 apud PETRAGLIA, 2008, p. 66-67).

Assim, comunicando esses conceitos numa teia complexa, onde estão em movimento as ideias do Homo sapiens sapiensdemens, juntamente com os três operadores da complexidade, atrelados ao tetragrama, constituem fundamentalmente a base do pensamento complexo, que abre os horizontes para a complexidade do mundo e sua perspectiva multidimensional. Fato é que somos contraditórios por natureza. A contradição está em nós, e nós, a cada escapada de uma cela, entramos em outras celas, abertas e, ao mesmo tempo, fechadas pelas incertezas do caminho.

O homem é o ser mais limitado que existe, já que o mais individualizado. Entretanto, ao mesmo tempo e por isso mesmo, é o ser cuja necessidade é a mais ilimitada, a mais universal. Esta contradição é o próprio tecido de nossa condição. Não foi senão com toques de varinha mágica que religiões e filosofias acreditaram suspender ou conciliar a contradição. De fato, o momento da reconciliação é o momento em que o pensamento passa ao ponto morto; suprimir o ânodo ou o cátodo significa interromper a eletrólise. Contudo a aceitação imbecilizada ou desesperada da contradição é uma espécie pior de morte intelectual.

O que fazer? Como dizer? É necessário ao mesmo tempo aceitar o que se recusa e recusar o que se aceita. É preciso exigir a totalidade e negá-la (MORIN, 2002b). "Somos seres infantis, 
neuróticos, delirantes e também racionais. Tudo isso constitui o estofo propriamente humano" (MORIN, 2002c, p. 59). Não há mais natureza congelada. A matéria tem uma história. Tudo que é vivo tem uma história. Tudo nasce, tudo morre. Tudo ressurge renovado em espírito, somos transformados e transformadores da realidade micro e macrocósmica. Rejuvenescemos nossas formas de pensar, agir e sentir o mundo quando realmente olhamos para dentro de nós; e percebemos que a mudança é fatal perante o porvir indeterminado. Neste acontecimento, justifica-se a frase: Estamos na complexidade real, da qual somos e fazemos parte..., estamos num devir cósmico, somos Homo complexus.

Nesses temposcomplexostempos, ${ }^{6}$ o homem já não se isola da harmonia coletiva, a fim de observar, sem que, por sua vez, não seja observado. Não há como produzir um conhecimento se isolarmos o sujeito de conhecimento de seu ambiente, pois que estaríamos voltados às hastes do orgulho e da fatalidade de sermos seres acabáveis na construção de nós mesmos e de uma contribuição para um conhecimento pertinente no e com mundo.

Justamente em meio aos caminhos das cisões, em meio à ciência determinista que promoveu a disjunção, acreditou-se "na possibilidade de eliminar o risco de erro, recalcando toda afetividade" (MORIN, 2002c, p. 20). Contudo, esta mesma ciência trouxe a nós outros uma noção de sujeito pautada numa ética complexa, pois "a afetividade pode asfixiar o conhecimento, mas também fortalecê-lo" (MORIN, 2002c, p. 20). Esta noção, podemos assim dizer, é extremamente imersa num paradoxo uno e múltiplo, pois assim caminhamos em natureza itinerante.

6 Não há como falar de sujeito sem falar de tempo. Bem como não há como falar de tempo sem contextualizá-lo no âmbito da Atualidade complexa, onde as ideias de presente, passado e futuro se entrelaçam num devir cósmico do "tempo irreversível" (MORIN, 2005). O neologismo propõe a problematização das fronteiras e a ultrapassagem do desconhecido e da descoberta, do medo e da audácia. Um caminhar concomitantemente sistêmico, hologramático, recursivo e auto-eco-organizador, que se reintroduz na teia dialógica a qual se configura o tempo. O humano demasiadamente humano, na complexidade do ser e do saber, na convicção de que nós fazemos parte do todo complexo com o Outro.

\section{Sujeitos complexus para tempos complexos}

Confundidas em várias vertentes, podemos observar a concepção de sujeito sendo desenvolvida aos extremos. Ora numa concepção de mãos dadas com o materialismo, concebendo o homem apenas nos limites homo faber e economicus, destituídos da subjetividade, afetividade, loucura, amor e poesia (MORIN, 2002b); e, por vezes outras, curvando a vara para o outro extremo, considerando apenas que a verdadeira e mais completa concepção de sujeito encontra-se definida no campo filosófico da metafísica, "onde o sujeito confunde-se com a alma, com a parte divina ou, pelo menos, com o que em nós é superior, já que nele se fixam o juízo, a liberdade, a vontade moral etc." (MORIN, 1996, p. 45). Assim sendo, institui-se um dualismo em nosso pensar, não sendo mera coincidência o nosso atual pensar dicotômico, no qual, pela ciência mecânica, fazemos de um lado uma instância determinista do sujeito, pautado apenas no físico, no biológico, no social ou cultural, "falecendo" assim o sujeito; e, de outro lado, ficamos no campo que aceita apenas aquilo que a razão do homem não é capaz de compreender, pautando-nos numa "falsa fé", a crença que ignora o desenvolvimento do homem e sua historicidade consigo mesmo e com o mundo, confiando apenas que o transcendental é a resposta para o sujeito em sua plenitude/inteligência.

Bem, diante desses extremos, seria óbvio dizer que é necessário um equilíbrio entre essas apresentações para compreendermos a noção de sujeito complexo. Contudo, numa reflexão mais profunda, que equilíbrio seria esse? Apenas somar um ao outro e dizer que um faz parte do outro e vice-versa? Responderemos com convicção: certamente que não! Pois que a complexidade por si só não admite que a Totalidade seja concebida como uma mera soma das partes. O que dizer então da noção de sujeito complexo?! Costumeiramente, nos afeiçoamos a alguém pela subjetividade encontrada em seus traços; e, dessa forma, deparamo-nos no/ com o erro de definir o Outro. Quando assim fazemos, estamos ainda imersos na cegueira de nossas verdades irrisórias, segundo as quais tentamos compreender o mundo. O Outro - que carrega dentro de si um universo - é muito mais complexo 
do que os estrondos de nossas filosofias. O mundo é muito maior do que as nossas verdades, filosofias e pensamentos! Nessa vida, melhor dizendo, em nossa vida alienada pelas reduções da natureza humana, poderiam nossas relações, construídas à luz da Modernidade, sufocar a relação conosco e com o Outro. Alguns conhecimentos fazem com que se diminuam as amizades e a amorosidade pelo mundo. A soma das afetividades não define a subjetividade do sujeito; a inclusão de nossas verdades no Outro não o define. Salienta-nos Morin (2002c) da necessidade da introspecção, um pensar que auxilia no desenvolvimento das nossas reflexões:

A prática mental do autoexame permanente é necessária, já que a compreensão de nossas fraquezas ou faltas é a via para a compreensão das do outro. Se descobrirmos que somos todos seres falíveis, frágeis, insuficientes, carentes, então podemos descobrir que todos necessitamos de mútua compreensão.

$\mathrm{O}$ autoexame crítico permite que nos descentremos em relação a nós mesmos e, por conseguinte, que reconheçamos e julguemos nosso egocentrismo. Permite que não assumamos a posição de juiz de todas as coisas. ${ }^{7}$ (MORIN, 2002c, p. 100).

Entre encontros e desencontros, entre desencontros e encontros, nossas relações e concepções de sujeito tornar-se-ão mais e mais necessárias na/com a complexidade real, enquanto sujeitos envoltos na seiva que alimenta a planta pela razão e emoção, na permanente e evolutiva troca de células doentes por vitalícias, na permanente ânsia por buscar a moralidade e a caridade sem interesses secundários, alimentando-nos assim em corpo e espírito pelos acontecimentos históricos que nos formam e dos quais fazemos parte. Justificamos, então, que a construção do sujeito não é apenas a simples soma de concepções de diversas áreas do conhecimento que tentam defini-lo, pois que, a cada instante, a cada devir cósmico, só pode ser descrito por aqueles e aquelas que a experienciam, e, ainda assim, essa descrição pelos próprios atores que percorrem este caminho poderia ser descrita hora menos, ou hora mais, do que o exato instante ocorrido, relevando e esclarecendo assim que a Totalidade pode ser mais ou menos do que a soma. Um átimo

\footnotetext{
7 "É um idiota", "É um crápula" são expressões que exprimem ao mesmo tempo a total incompreensão e a pretensão à soberania intelectual e moral.
}

de segundo pode fazer a diferença pela estrada a ser percorrida. A vida é constituída por instantes, sejam quais forem; estes se unem nas cascatas do devir, onde o "Eu", em congruência com "tu", se fundem na práxis do único conhecimento válido nestes temposcomplexostempos: o que se alimenta de incerteza e que aceita como único pensamento que vivifica, a verdadeira ética da compreensão que extirpa a qualquer hora nossa petulância.

Nessa formação do sujeito complexo, um paradoxo está em nós, e a noção de sujeito não poderia escapar ao princípio dialógico. Aqui, onde esta noção entrelaça os princípios da complexidade, não poderíamos deixar de nos submeter à pressão simultânea das ideias contrárias, trazendo então a complementaridade dos contrários.

Vivemos um paradoxo íntimo, e essas questões desestabilizam as possíveis visões que nós construímos acerca de um mundo redutível, pois que, ao mesmo tempo, surge neste fervilhar de ideias um possível anúncio complexo que não podemos ter a audácia em dizer que é um guia para verdade e que derruba todos os equívocos históricos elaborados até então. No entanto, uma nova possibilidade de concebermos o sujeito fora da disjunção e do determinismo do paradigma enraizado em nossa cultura está expressada em viva voz na religação do sujeito com o objeto e com a natureza, mostrando então uma maneira complexa não só de se fazer pesquisa, mas de vivenciarmos a natureza existente em nós. Podemos assim dizer que há uma inseparabilidade na relação sujeito/objeto.

O conhecimento objetivo necessita do sujeito, da interação subjetiva e também de projeções das estruturas mentais de sujeito. O conhecimento não é um espelho, uma fotografia da realidade. $\mathrm{O}$ conhecimento é sempre tradução e reconstrução do mundo exterior e permite um ponto de vista crítico sobre o próprio conhecimento. Por esta razão eu disse que o conhecimento, sem o conhecimento do conhecimento, sem a integração daquele que conhece, daquele que produz o conhecimento, e o seu conhecimento é um conhecimento mutilado. [...] Integrar qualquer conhecimento é uma necessidade epistemológica. (MORIN, 2008c, p. 53).

Aqui, o ser inconcluso e o fazer o caminho ao andar são os artífices que nos impulsionam a tratar do sujeito, para o qual Morin (2002a, p. 118) “pro- 
põe uma definição não partindo da afetividade, não do sentimento, mas de uma base bio-lógica". Para tanto, uma noção de sujeito mais elaborada necessita que falemos da autonomia, da auto-organização e do conceito de indivíduo, uma tríade inseparável no entrelaçamento do sujeito.

A autonomia que o pensamento complexo contempla vai além da ideia de liberdade absoluta, mas envolve uma autonomia que depende de seu meio ambiente (MORIN, 2002a). A ideia de autonomia está inseparável da auto-organização. Esta última nos mostra o quão os sujeitos são capazes de emergirem ao mesmo tempo no/com o mundo a partir de sua auto-organização, intrínseca à autonomia e à dependência. "Para transformar-se e conhecer-se, o sujeito necessita de um objeto. É a partir dessa dependência que o sujeito e o objeto emergem da realidade complexa, assim como se observa na relação recíproca e inseparável: sistema auto-organizador e ecossistema" (PETRAGLIA, 2008, p. 69). Portanto, ao fundir a autonomia e a dependência no devir, esta capacidade do sujeito o torna "auto-organizador de seu processo vital e não exclui a dependência relativa ao mundo exterior, aos grupos, à sociedade e ao ecossistema. Então a auto-organização é na verdade auto-eco-organização, porque a transformação extrapola o seu ser" (PETRAGLIA, 2008, p. 71).

O "pioneiro do pensamento complexo" explana sobre a noção de sujeito a partir de uma elaboração sobre indivíduo, a partir de uma abordagem biológica, na qual não podemos dizer que é a noção de sujeito propriamente dita, mas parte deste todo, tal como um ponto no holograma complexo que está no humano do humano.

A concepção de sujeito perpassa a organização viva. Dessa forma, a biologia molecular e genética nos deram elementos para compreendermos essa organização. O indivíduo, nos revela Petraglia (2008), constitui-se de elementos químicos, além de sermos parte do ecossistema e da sociedade, sendo estes respectivamente nomeados por Edgar Morin como infra, extra, supra e metaindividuais. Essas características, ao mesmo tempo em que nos singularizam, nos diferenciam, "não enquanto membro de uma categoria pertencente à espécie, mas como autor de seu processo organizador, que o torna sujeito" (PETRAGLIA, 2008, p. 67).
A noção de indivíduo não é absolutamente fixa e estável, pois que tendências biológicas já o demonstraram. "Para uma delas, a única realidade é o indivíduo, porque, fisicamente, vemos apenas indivíduos, nunca a espécie; para a outra, a única realidade é a espécie, já que os indivíduos não passam de amostras efêmeras" (MORIN, 2002a, p. 119).

Para nós, existe um elo complexo na concepção de indivíduo, em que uma recursividade funda-se na dinâmica existente entre sujeito e objeto. Essas noções, aparentemente antagônicas, terão mais coerência na realidade ao se complementarem. Dessa forma, busquemos no princípio recursivo uma condição de relacionarmos o indivíduo e a espécie, e não abordarmos um em detrimento do outro; assim como nos diz Morin (2002a, p. 119), "podemos aplicar o mesmo raciocínio a relação entre indivíduo/sociedade". Ratifica a ideia Morin (1996, p. 47-48) ao dizer que:

$\mathrm{O}$ individuo é, evidentemente, um produto; e o produto, como ocorre com todos os seres sexuados, do encontro entre um espermatozoide e um óvulo, ou seja, de um processo de reprodução. Mas esse produto é, ele mesmo, produtor no processo que concerne a sua progenitura; somos produtos e produtores, num ciclo rotativo da vida. Desse modo, a sociedade é, sem dúvida, o produto de interações entre indivíduos. Essas interações, por sua vez, criam uma organização que tem qualidades próprias, em particular a linguagem e a cultura. E essas mesmas qualidades retroatuam sobre os indivíduos desde que vêm ao mundo, dando-lhes linguagem, cultura, etc. Isso significa que os indivíduos produzem a sociedade, que produz os indivíduos.

Assim, entrelaçamos na teia a tríade que necessita anteceder a ideia de sujeito propriamente dita. Necessário, pois, pensarmos recursivamente para concebermos esta relação paradoxal. O indivíduo é um objeto incerto. Pois que, ao mesmo tempo em que de um ponto de vista se é tudo, a partir do outro não se é nada, se ofusca. De produtor, converte-se em produto, de causa, em efeito e vice-versa (MORIN, 1996). Dessa maneira, podemos compreender a autonomia do indivíduo, mas sem perder de vista a dependência, pois, como dissemos nas linhas que antecederam a descrição dos princípios do pensamento complexo, neste mundo incerto, cujas rela- 
ções oscilam, o único absoluto que nós podemos admitir é a presença do amor, na medida em que cansamos de nossa própria sapiência, e esforçamo-nos para domar o nosso lado obscuro. Assim, pois, a autonomia do indivíduo é extremamente relativa e complexa (MORIN, 1996).

Podemos agora imergir na noção do sujeito. Este vai além da noção de indivíduo e remete-nos à ideia de que cada ser vivo, ainda que esteja na/ com o princípio recursivo, é um ser único em seu aspecto de subjetividade. "Na relação com o Outro, a autotranscendência do sujeito o permite superar para si mesmo a ordem da realidade, para além de sua própria esfera e de seu ambiente, alterando-a a partir de sua dimensão ética, que irá nortear os seus valores" (PETRAGLIA, 2008, p. 69).

Não evoluímos sem o Outro e o objeto. Somos partes qualitativas do todo em que vivemos, mas essas qualidades das partes somente se tornam reais quando estão se inter-relacionando com o todo. Nós evoluímos, as nossas células a mais ou menos a cada quatro anos já não são mais as mesmas, já se renovaram. Dessa forma, quando me refiro a "mim", estou me referindo ao "eu" que está em constante mudança, em movimento, mas também ao "eu" que vai ser sempre o mesmo, porém, a cada dia, acrescido de ideias e culturas e conhecimentos, que são intrinsecamente parte de "mim", que sou "eu" e "Eu". Para tanto, digamos com Edgar Morin (2002a, p. 119) que:

[...] É preciso pensar que toda organização biológica necessita de uma dimensão cognitiva. Os genes constituem um patrimônio hereditário de natureza cognitiva/informacional da célula. Da mesma maneira, o ser vivo, seja ele dotado ou não de um sistema neuro-cerebral retira informações de seu meio ambiente e exerce uma atividade cognitiva intrínseca de sua prática de ser vivo. Ou seja, a dimensão cognitiva é indispensável à vida.

Avancemos no que tange à concepção do ser biológico. Então, a dimensão cognitiva, nos esclarece Morin (2002a), é computacional. O “arquiteto da complexidade" traz este conceito, este cômputo, que podemos dizer que é necessário para a existência do sujeito, isto é, a condição de se posicionar no centro de seu mundo. A saber:

A natureza da noção do sujeito tem a ver com a natureza singular de sua computação, desconhecida por qualquer computador artificial que possamos fabricar. Essa computação do ser individual é a computação que cada um faz de si mesmo, por si mesmo e para si mesmo. É um cômputo. O cômputo é o ato pelo qual o sujeito se constitui posicionando-se no centro de seu mundo para lidar com ele, considerá-lo, realizar nele todos os atos de preservação, defesa etc. (MORIN, 2002a, p. 120).

Entretanto, a noção de sujeito não se resume no cômputo. Admite-se também o egocentrismo, o posicionar-se no centro de seu mundo. Aquilo que sabemos como é, mas não se pode vê-lo, aquilo que sabemos de sua existência, mas não podemos tocá-lo: são os medos que atormentam; são as dúvidas que temos sobre o que as pessoas sentem por nós; a nossa relação com a morte; e a nossa relação com a vida. Essas questões nos auxiliaram a desenvolver esta discussão, mas não podemos perder de vista que, muitas das vezes, elas são encobertas pelas máscaras que colocamos para fingir, e/ou fugir de nosso próprio "Eu". Este "Eu" "é o pronome que qualquer um pode dizer, mas ninguém pode dizê-lo em meu lugar" (MORIN, 2002a, p. 120).

A noção de sujeito considera o antagonismo vital que está no homem. Considera a figura egocêntrica representada pelo "Eu" (subjetivo) e o "eu" (sujeito objetivado), a objetivação do ser que ocupa esse espaço egocêntrico, sendo que o "Eu" e o "eu" são identidades indissociáveis. Daí compreendemos que o "eu" precisa da relação com o "tu", pois ambos são pertencentes ao mundo. "O sujeito emerge ao mesmo tempo em que o mundo a partir de sua auto-organização, que é a capacidade que o ser humano tem de transformar-se sempre" (PETRAGLIA, 2008, p. 68). Mergulhando neste movimento complexo, vemos que princípio é indispensável, uma vez que permite qualquer tratamento objetivo de si mesmo. O princípio hologramático aqui se inscreve. O "Eu" e "eu" que são indissociáveis, admitindo nestas circunstâncias os objetos como integrantes a nós.

Eis, portanto, um princípio que, por esta separação/unificação do "Eu" subjetivo e do "eu" objetivo, permite efetivamente todas as operações. Este princípio comporta a capacidade de se referir ao mesmo tempo a "si" (autorreferência) e ao mundo exterior (exorreferência) - de distinguir, portanto, o que é exterior a si. "Auto-exo-referência" quer 
dizer que eu posso distinguir entre o "eu" e o "não-eu", o "Eu" e o não-"Eu", bem como entre o "eu" e os outros "eu", o "Eu" e os outros "Eu" (MORIN, 2002a).

O sujeito aparece com o cômputo e com o egocentrismo, onde a noção de sujeito está indissociavelmente unida a esse ato, no qual não só se é a própria finalidade de si mesmo, mas em que também se é autoconstitutivo da própria identidade. (MORIN, 1996, p. 49).

Caminhando para a complexidade do sujeito, buscamos, na vida/teoria presente pelas andanças de Edgar Morin, um sentimento que foi talvez o maior responsável pela criação da teoria da complexidade e de sua ontologia: o convívio com a morte. Uma angústia se instalou em seu ser desde muito cedo. Parecia que lutava para nascer, pois sua mãe houvera tentado um aborto em sua gestação, na luta por sua própria sobrevivência. Aos quatro anos de idade, sofria pela dificuldade de respirar. No entanto, o medo constante tornou-se aliado, e a morte, ao invés de ser concebida como uma espécie de silêncio absoluto, pronunciava infatigavelmente um nascimento. Não o nascimento do ser biológico, mas o nascimento para a compreensão, a compreensão do humano. Não o ser concebido pela racionalidade científica que negligencia a morte, e se contenta em reconhecer o homem pela ferramenta, ou seja, como Homo faber, mas a possibilidade e a necessidade emergente de considerar o homem como um humano. Dessa forma,

De pouco serve declarar que a ferramenta humaniza a natureza, e que a sobrevivência humaniza a morte, enquanto o humano continuar sendo um conceito instável. Só poderemos compreender a humanidade da morte, compreendendo a especificidade do humano. Só então poderemos ver que a morte, como a ferramenta, afirma o indivíduo, o prolonga no tempo, assim como a ferramenta no espaço, também procura adaptá-lo ao mundo, exprime a mesma inadaptação do homem ao mundo, as mesmas possibilidades conquistadoras do homem em relação ao mundo. (MORIN, 1997, p. 24).

Esse é o ponto crucial dessa jornada ontológica, que necessariamente caminhou pelos princípios que compõem o pensamento complexo, pois a noção do sujeito complexo comporta necessariamente em considerar que cada ser é único, e a sua subje- tividade o difere dos Outros, a partir da aceitação de si mesmo.

$\mathrm{O}$ fato de termos um corpo biológico extremamente complexo não significa que podemos nos limitar em dizer que ele é a causa inteligente da vida em si, do sujeito em si. Fato também é que não podemos reduzir a noção de sujeito à subjetividade, ou à afetividade, ou à consciência. Este último não se limita nas potencialidades biológicas de nosso cérebro. O ser humano se distingue dos outros, do sistema aberto e vivente em que se encontra, justamente pela sua capacidade reflexiva e de sua consciência. Para Morin (2002a, p. 126), "a consciência é a qualidade humana última e, sem dúvida, mais preciosa, pois o que é último é, ao mesmo tempo, o que há de melhor e de mais frágil. E, de fato, a consciência é extremamente frágil e, em sua fragilidade, pode enganar-se muitas vezes". E é aqui, na presença do humano demasiado humano, que aparece um fator fundamental na ontologia de Edgar Morin: a presença do "duplo", "espectro objetivo e imaterial de seu próprio ser, acompanha-o incessantemente e é reconhecido na sombra, no reflexo" (MORIN, 2002a, p. 125).

Existe, e assim o vemos, um nível prévio para compreendermos o sujeito, e não podemos ainda cair no equívoco de concebê-lo pela consciência. Pois bem, aqui, neste nível, não podemos reduzi-la, mas entrelaçá-la junto à subjetividade e à afetividade: a liberdade. No entanto, temos uma bifurcação de liberdade. Uma permite estabelecermos escolhas, e a outra só a admite com uma condição externa, imprescindível, a fim de sabermos se as condições são possíveis.

Todavia, em meio à demência herdada da Modernidade, em meio à cega sapiência, surge, pela mesma ciência que expulsou o humano do humano, uma noção mais complexa do sujeito. Morin (1996, p. 53) nos presenteia ao dizer que:

Finalmente, existe em nossa subjetividade humana esse lugar habitado pelas noções de alma, de espírito, animus, anima, e temos o sentimento profundo de uma insuficiência da alma que só pode satisfazer o outro sujeito. E, no fundo, com a relação de amor, no sentimento de amor, está a ideia de que o outro restitui a nós mesmos a plenitude de nossa própria alma, permanecendo totalmente diferente de nós mesmos. E nós mesmos, ainda sendo outro. Tenho 
aqui, então, dois níveis de subjetividade. Muitas vezes se acreditou encontrar o fundamento do conceito de sujeito nesses níveis humanos, que só podem aparecer porque há um nível prévio, bio-lógico, do conceito de sujeito. E cometemos o erro de reduzir a subjetividade, seja à afetividade e à contingência, seja à consciência.

Temos então que o sujeito é único para si mesmo e age como centro de referência. "Sua autotranscendência, que lhe permite ir além de si mesmo e questionar-se, determina seus princípios de lógica e ética, fazendo-o agir considerando sua afetividade e suas verdades" (PETRAGLIA, 2008, p. 71).

Precisamos reconhecer que todos e todas não são somente atores no/com o mundo, mas autores, envoltos na capacidade de cognição, autonomia/ dependência. Lembremos que não basta apenas que somemos as concepções de sujeito para que tornemos de fato a noção de sujeito complexo, mas que a tornemos uma concepção complexa do sujeito ao nos aceitarmos imersos nessa complexidade. A complexidade está em dar a multiplicidade ao uno, e o uno à multiplicidade. Derrubemos a postura esquizofrênica do pensamento Moderno, cujas opções somente têm sido o pensamento disjunto da subjetividade/objetividade, enfim, a redução do sujeito. Não partamos do simples para compreender o complexo, pois que o simples aqui torna-se infame ao considerarmos que todas as partes possuem suas emergências complexas. A humanidade em nós somente foi tentada a ser extinguida, mas podemos dizer que a complexidade estava apenas adormecida no tempo, esperando a propícia cascata de acontecimentos simultâneos fervilhar na Atualidade, religando o sujeito no devir dos temposcomplexostempos.

\section{REFERÊNCIAS}

AZIBEIRO, Nair Esperança. Educação intercultural e complexidade: desafios emergentes a partir das relações em comunidades populares. In: FLEURI, R. M. (Org.). : mediações necessárias. Rio de Janeiro: DP\&A, 2003. p. 85-107.

MORIN, Edgar. A cabeça bem-feita: repensar a reforma, reformar o pensamento. 6. ed. Rio de Janeiro: Bertrand Brasil, 2002a.

. Amor, poesia, sabedoria. 8. ed. Rio de Janeiro: Bertrand Brasil, 2008a.

. A noção de sujeito. In: SCHNITMANN, D. F (Org.). Novos paradigmas, cultura e subjetividade. Porto Alegre: Artes Médicas, 1996. p. 45-55.

Ciência e consciência. 12. ed. Rio de Janeiro: Bertrand Brasil, 2008b.

Da necessidade de um pensamento complexo. In: MARTINS, F. M.; SILVA, J. M. (Org.). Para navegar no século XXI: tecnologias do imaginário e cibercultura. 3. ed. Porto Alegre: Sulinas/Edipucrs, 2003. p. 1-27.

Em busca dos fundamentos perdidos - textos sobre o marxismo. Porto Alegre: Sulina, 2002b.

Introdução ao pensamento complexo. 3. ed. Porto Alegre: Sulina, 2007.

O enigma do homem. Rio de Janeiro: Zahar, 1975.

O homem e a morte. Rio de janeiro: Imago, 1997.

O método I: a natureza da natureza. 2. ed. Porto Alegre: Sulina, 2005.

Os sete saberes necessários à educação do futuro. 5. ed. São Paulo: Cortez, 2002c.

Saberes globais e saberes locais: o olhar transdisciplinar. Rio de Janeiro: Garamond, 2008c.

PETRAGLIA, Isabel. Edgar Morin: a educação e a complexidade do ser e do saber. 10. ed. Petrópolis, RJ: Vozes, 2008. PRIGOGINE, Ilya. Do ser ao devir. São Paulo: Editora UNESP, 2002.

RAMOS, Roberto. A educação e o conhecimento: uma abordagem complexa. Educar, Curitiba, n. 32, p. 75-86, 2008. 